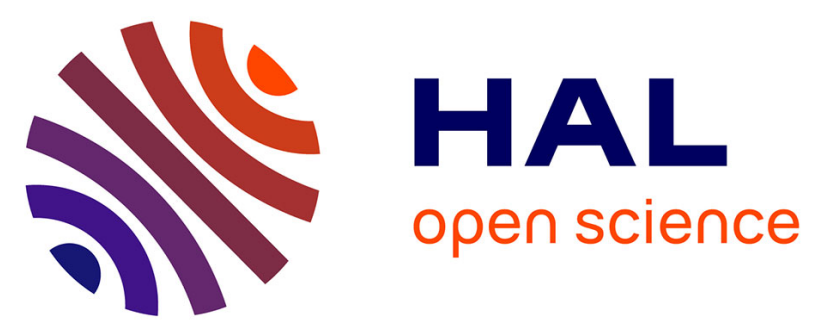

\title{
Vapor Pressure Measurements of Hydroxyacetaldehyde and Hydroxyacetone in the Temperature Range (273 to 356) $\mathrm{K}$
}

\author{
M. Petitjean, E. Reyès-Perez, D. Perez, Ph. Mirabel, S. Le Calve
}

\section{- To cite this version:}

M. Petitjean, E. Reyès-Perez, D. Perez, Ph. Mirabel, S. Le Calve. Vapor Pressure Measurements of Hydroxyacetaldehyde and Hydroxyacetone in the Temperature Range (273 to 356) K. Journal of Chemical and Engineering Data, 2010, 55 (2), pp.852-855. 10.1021/je9004905 . hal-02308893

\section{HAL Id: hal-02308893 \\ https://hal.science/hal-02308893}

Submitted on 21 Dec 2020

HAL is a multi-disciplinary open access archive for the deposit and dissemination of scientific research documents, whether they are published or not. The documents may come from teaching and research institutions in France or abroad, or from public or private research centers.
L'archive ouverte pluridisciplinaire HAL, est destinée au dépôt et à la diffusion de documents scientifiques de niveau recherche, publiés ou non, émanant des établissements d'enseignement et de recherche français ou étrangers, des laboratoires publics ou privés. 


\title{
Vapour pressure measurements of hydroxyacetaldehyde and hydroxyacetone in the temperature range (273 to 356$) \mathrm{K}$.
}

\author{
Petitjean M., Reyès-Pérez E., Pérez D., Mirabel Ph. and Le Calvé S. * \\ Laboratoire des Matériaux, Surfaces et Procédés pour la Catalyse (LMSPC, UMR 7515 \\ CNRS/UdS), 25 rue Becquerel, 67087 Strasbourg Cedex 02, FRANCE
}

\begin{abstract}
Vapour pressures of ethylene glycol, hydroxyacetaldehyde and hydroxyacetone were measured by using a standard closed system equipped with a vacuum line, built recently in our laboratory.

First, our vapour pressures measurements of ethylene glycol and their excellent agreement with the literature in the studied temperature range, i.e. (308 to 385) K, permitted us to validate our experimental set-up and procedure.

The data obtained in the temperature ranges (296 to 356) K and (273 to 304) K were very satisfactorily (Absolute Relative Deviations (ARD) $<2.5 \%$ ) fitted according to the Antoine's equation: $\log _{10}\left(P_{\text {hydroxyacetaldehyde }}^{\circ} \mathrm{Pa}\right)=12.96 \pm 0.82-(3657 \pm 238) / T / K$ and $\log _{10}$ $\left(P_{\text {hydroxyacetone }}^{\circ} \mathrm{Pa}\right)=10.13 \pm 0.06-(2201 \pm 153) / T / K$. Then, the resulting vapour pressures of both hydroxyacetaldehyde and hydroxyacetone at $293 \mathrm{~K}$ were $P^{\circ}=(3.0 \pm 0.2) \mathrm{Pa}$ and $P^{\circ}=$ $(415 \pm 20) \mathrm{Pa}$ for hydroxyacetaldehyde and hydroxyacetone, respectively. The quoted errors correspond to $2 \sigma$ obtained from the least square fit analysis and the estimated systematic relative error of $5 \%$.

Finally, these experimental expressions of temperature dependences of $P^{\circ}$ permitted then to derive the enthalpy of vaporization for both compounds.
\end{abstract}

Keywords: vapour pressure, Antoine's equation, hydroxyacetone, hydroacetaldehyde, glycolaldehyde, ethylene glycol, enthalpy of vaporization.

* Corresponding author. Fax: +33-(0)3-90-24-04-02. E-mail address: slecalve@unistra.fr 


\section{Introduction}

Hydroxyacetone $\left(\mathrm{HOCH}_{2} \mathrm{C}(\mathrm{O}) \mathrm{CH}_{3}\right)$ and hydroxyacetaldehyde $\left(\mathrm{HOCH}_{2} \mathrm{CHO}\right)$ are atmospheric pollutants of particular interest. Hydroxyacetone is produced in the atmosphere mainly from the $\mathrm{OH}$-initiated oxidation of isoprene, the main non-methane hydrocarbon in the troposphere ${ }^{1-3}$. Hydroxyacetaldehyde, usually named glycolaldehyde, is also formed in situ in the atmosphere from the oxidation of several volatile organic compounds (VOCs) including ethene, 2-methyl-3-buten-2-ol, and isoprene. ${ }^{4-7}$ Once produced in the atmosphere, these two hydroxyl carbonyls compounds have a potentially large atmospheric impact since they lead, in the upper troposphere, to $\mathrm{HO}_{\mathrm{X}}$ radicals known to increase the oxidizing capacity of the atmosphere and therefore they can influence the ozone budget. ${ }^{8}$

So far, hydroxyacetaldehyde and hydroxyacetone have not been considered to be significant aerosol constituents since it is assumed that these compounds have relatively high vapour pressures. However, recent field observations indicate that they are important atmospheric aerosol constituents. For example, Matsunaga et al., $2005{ }^{9}$ provide evidence that hydroxyacetone, hydroxyacetaldehyde (and methylglyoxal) contribute significantly to organic aerosols, (10 to 120) $\mathrm{Tg}$ annually. These findings have been confirmed, at least for hydroxyacetaldehyde, by Angove et al. $2006^{10}$ in smog chamber experiment. Note that, in this work, Angove et al. (2006) ${ }^{10}$ report an estimated value of $5.3 \mathrm{kPa}$ for the equilibrium vapour pressure $P^{\circ}$ of hydroxyacetaldehyde at $298 \mathrm{~K}$, while Butler et al. (2001) ${ }^{11}$ report also an estimated value of $4 \mathrm{~Pa}$ at room temperature. These two estimated values differ by more than two orders of magnitude. The situation is even worst for hydroxyacetone for which, to our knowledge, only an estimated upper limit exists i.e. $P^{\circ}<0.5 \mathrm{kPa}$ at room temperature. ${ }^{12}$

The precise knowledge of the equilibrium vapour pressure of a component is important to predict its partitioning between the gas and particle phases in the atmosphere ${ }^{13}$. In addition, the saturation vapour pressure $P^{\circ}$ can also be used to estimate Henry's Law constant that represents the partitioning between the gas and the aqueous phases at equilibrium. These partitionings are key physical properties to understand and predict the behaviour of a component in the environment. ${ }^{14-16}$

The main goal of this work is therefore to provide accurate experimental vapour pressures for both hydroxyacetone and hydroxyacetaldehyde. For this, our experimental set-up based on previous static devices ${ }^{17}$ was built and validated by vapour pressures measurements of ethylene glycol between (308 and 385) K. 


\section{Experimental section}

\section{Chemicals}

Ethylene glycol (> $99.5 \%$ ) and solid hydroxyacetaldehyde dimer (> $99 \%$ ) were purchased from Merck and Aldrich, respectively. Hydroxyacetone (> $95 \%$ ) was provided by Alfa Aesar. Before use, hydroxyacetaldehyde dimer was melted at temperatures ranging between (80 and 90) ${ }^{\circ} \mathrm{C}$ for more than $2 \mathrm{hrs}$ in order to obtain hydroxyacetaldehyde monomer. ${ }^{18}$ Hydroxyacetaldehyde monomer was then kept as limpid liquid even when temperature decreased typically down to $293 \mathrm{~K}$.

To eliminate the effect of gaseous impurities, all the compounds were further purified by freeze-pump-thaw cycles using liquid nitrogen/ethanol baths at different temperatures and a vacuum pump $(<0.02 \mathrm{~Pa})$.

\section{Apparatus and Procedure}

The experimental setup, shown schematically in Figure 1, is a static vapour-liquid equilibrium apparatus. It consists of a Pyrex flask containing the solid or liquid sample, connected to the vacuum line with a glass/metal connection (Caburn MDC®). It includes also a thermostatic bath, temperature and pressure measurement devices and a vacuum system.

The pressure was measured in the equilibrium cell by a capacitance manometer (Edwards ${ }^{\circledR}, 622$ Barocel, ranges 0 to $1000 \mathrm{~Pa}$ and 0 to $10000 \mathrm{~Pa}$ ) coupled to a digital indicator $\left(\mathrm{BOC}\right.$ Edwards $\left.{ }^{\circledR}\right)$ giving uncertainties of $\left(0.1+0.15 \mathrm{P} / \mathrm{P}^{*}\right) \mathrm{Pa}$ and $\left(1+0.15 \mathrm{P} / \mathrm{P}^{*}\right)$ $\mathrm{Pa}$, where $\mathrm{P}^{*}=100 \mathrm{~Pa}$, for 0 to $1000 \mathrm{~Pa}$ and 0 to $10000 \mathrm{~Pa}$ ranges, respectively.

Except for the vacuum system, the entire device was placed in an oven maintained at a temperature slightly higher than that of the oil bath in which the Pyrex flask was immersed, in order to avoid any vapour condensation on the tube walls. Both bath and oven temperatures were measured with thermocouples $\mathrm{K}$ coupled to a laboratory thermometer (Allcat Instruments $\left.{ }^{\circledR}\right)$ having an accuracy of $\pm 0.25 \%$ of the reading values in ${ }^{\circ} \mathrm{C}$. In addition, the thermocouples were calibrated by the manufacturer few months before the measurements and were checked by dipping them into an ice bath maintained to $273.15 \mathrm{~K}$.

The vacuum system (not shown) is composed of a combination of turbomolecular/vacuum pump (Edwards® High Vaccum, type EXC120/ type RV8) and a liquid nitrogen trap. Two control valves allow to either isolating the sample from the vacuum system (control valve 1) or isolating the equilibrium cell from the vacuum system, leading to the establishment of an equilibrium between the liquid and gas phases (control valve 2). 


\section{Results and discussion}

\section{Ethylene glycol}

The vapour pressure of ethylene glycol was measured in the temperature range $308-385$ $\mathrm{K}$ in order to validate the experimental set-up.

After degassing of ethylene glycol in situ in the pyrex flask, the measurements of the saturation vapour pressure were performed by first establishing a highly stable vacuum in the equilibrium cell. The control valve (2) was then rapidly closed allowing the establishment of equilibrium between the liquid phase and the gas phase while the pressure values in the equilibrium cell were monitored on a computer. Figure 2 illustrates a typical data plot obtained for a given temperature (here at $326.1 \mathrm{~K}$ ).

As shown in Figure 2 (see solid line), the pressure increased quickly at the beginning of the experiment and after a time scale of about $15 \mathrm{~min}$, it leveled off meaning that the liquid phase reached equilibrium with the gas phase. Nevertheless when this equilibrium was reached, the pressure continued to slowly increase linearly with time due to the presence of leaks (see dash-do-dot line in Figure 2). This leak is specific to equipment used in our system, i.e. vacuum fittings with viton seals (NW references, @Edwards). The pressure reading at a given experimental time was then corrected by subtracting the leak contribution as follows:

$$
P_{\text {corrected }}=P-\mathrm{v} \times t
$$

where $P$ is the reading pressure, $v$ is the leak rate and $t$ is the time from the beginning of experiment.

The leak rate $v$ was obtained from the slope of the linear part of the plot of $P$ versus $t$ (see dash-dot-dot line in Figure 2). The plot of the resulting corrected pressures (see solid line in Figure 2) reaches now a horizontal plateau that corresponds to the saturation vapour $P^{\circ}$ at a given temperature.

Similar experiments were repeated for temperatures ranging between $308 \mathrm{~K}$ and $385 \mathrm{~K}$ (see Table 1). The relative errors on the vapour pressure measurements correspond to $2 \sigma+5 \%$, where $\sigma$ is obtained from the least square linear fit analysis and $5 \%$ is the estimated systematic relative error. The resulting relative errors varied between (5 and 7) \%.

Since the plot of $\log _{10} P^{\circ}$ versus $1 / T$ showed a linear behaviour (see Figure 3), the results were fitted according to a simplified Antoine's equation:

$$
\log _{10}\left(P^{\circ} / P a\right)=(12.02 \pm 0.72)-\frac{3257 \pm 204}{(T / K)}
$$


where the quoted errors correspond to $2 \sigma$ obtained from the least square linear fit analysis and the estimated systematic relative error of $5 \%$.

The absolute relative deviation (ARD) was defined as follows:

$$
A R D=\frac{1}{n} \sum_{i=0}^{n}\left[\frac{\left|P^{0}-P_{\text {calc }}^{0}\right|}{P^{0}}\right]_{i}
$$

where $n$ is the total number of experimental data points and $P_{\text {calc }}^{\circ}$ is the calculated vapour pressure.

According to Eq. 2, the ARD value is less than 2\%. It appears therefore that our data can be conveniently fitted according to the simplified Antoine's equation.

The vapour pressure of ethylene glycol derived from the experimental simplified Antoine's equation is $P^{\circ}=(8.02 \pm 0.41) \mathrm{Pa}$ at $293 \mathrm{~K}$.

The enthalpy of vaporization $\Delta_{v a p} H$ is constant on the investigated temperature range. This later, derived from the slope of $\log _{10} P^{\circ}$ versus $1 / T$, is then found to be $(62.4 \pm 4.0) \mathrm{kJ} \mathrm{mol}^{-1}$.

\section{Comparison with the literature}

The equation derived from the literature ${ }^{19}$ in the same temperature range is:

$$
\log _{10}\left(P^{\circ}{ }_{l i t} / P a\right)=(12.22 \pm 0.69)-\frac{3325 \pm 193}{(T / K)}
$$

The calculated literature values ${ }^{19}$ are summarized in Table 1 together with our experimental values $\left(P^{\circ}\right)$. Our extrapolated experimental value at $293 \mathrm{~K}\left(P^{\circ}=8.02 \pm 0.41 \mathrm{~Pa}\right)$ is in good agreement with that of Stull et al. $\left(P^{\circ}{ }_{l i t}=7.45 \pm 0.38 \mathrm{~Pa}\right)$ at the same temperature. In the temperature range (308 to 385$) \mathrm{K}$, the differences between the two set of data are at most $5 \%$, indicating that our experimental set up is suitable to measure equilibrium vapour pressure with good accuracy.

Similarly, our vaporization enthalpy of $(62.4 \pm 4.0) \mathrm{kJ} \mathrm{mol}^{-1}$ is consistent with the literature values of $65.6 \pm 0.3 \mathrm{~kJ} \mathrm{~mol}^{-120}, 67.6 \mathrm{~kJ} \mathrm{~mol}^{-1}{ }^{21}$ and $61.9 \mathrm{~kJ} \mathrm{~mol}^{-1}{ }^{22}$

\section{Hydroxyacetone and hydroxyacetaldehyde}

Once the set-up validated, saturation vapour pressures of hydroxyacetaldehyde and hydroxyacetone were measured in the temperature ranges (296 to 356) $\mathrm{K}$ and (273 to 304) K, respectively. The results are listed in Table 2. The relative uncertainties on the measurements varied between (5 and 13) \% for hydroxyacetaldehyde and (5 and 7) \% for hydroxyacetone.

The vapour pressures were fitted according to the Antoine's equation: 


$$
\begin{aligned}
& \log _{10}\left(\mathrm{P}^{0}(\text { hydroxyac etaldehyde }) / \mathrm{Pa}\right)=(12.97 \pm 1.70)-\frac{3668 \pm 1101}{(\mathrm{~T} / \mathrm{K})+(0.45 \pm 48)} \\
& \log _{10}\left(P^{0}(\text { hydroxyac etone }) / \mathrm{Pa}\right)=(10.12 \pm 2.88)-\frac{2193 \pm 1657}{(T / K)-(0.46 \pm 10)}
\end{aligned}
$$

where the quoted uncertainties correspond to $1 \sigma$ obtained from the least square fit analysis.

Similarly to ethylene glycol, the data of $\log _{10} P^{\circ}$ versus $1 / T$ can conveniently be fitted, as shown in Figure 4, with a two parameters Antoine's equation:

$$
\begin{aligned}
& \log _{10}\left(P^{0}(\text { hydroxyac etaldehyde }) / \mathrm{Pa}\right)=(12.96 \pm 0.82)-\frac{3657 \pm 238}{(T / K)} \\
& \log _{10}\left(P^{0}(\text { hydroxyac etone } / \mathrm{Pa})\right)=(10.13 \pm 0.06)-\frac{2201 \pm 153}{(T / K)}
\end{aligned}
$$

where the quoted errors correspond to $2 \sigma$ obtained from the least square fit analysis and include a estimated systematic relative error of $5 \%$.

Again, the values of ARD determined according to eq. (2), found to be equal to $2.0 \%$ and $2.5 \%$ for hydroxyacetone and hydroxyacetaldehyde, respectively, confirm that the experimental values can be conveniently fitted according to the simplified Antoine's equation. These equations permit then to derive the vapour pressures of both hydroxyacetaldehyde and hydroxyacetone at $293 \mathrm{~K}$, which were $P^{\circ}=(3.0 \pm 0.2) \mathrm{Pa}$ and $P^{\circ}=(415 \pm 20) \mathrm{Pa}$ for hydroxyacetaldehyde and hydroxyacetone, respectively.

Similarly to ethylene glycol, the enthalpies of vaporization of both compounds were derived from the Clausius-Clapeyron's equation: $\Delta_{v a p} H$ (hydroxyacetaldehyde) $=(70 \pm 5) \mathrm{kJ}$ $\mathrm{mol}^{-1} \Delta_{\text {vap }} H$ (hydroxyacetone $)=(42 \pm 3) \mathrm{kJ} \mathrm{mol}^{-1}$.

\section{Comparison with the literature}

As noted in the introduction, the literature data concerning the vapour pressures of hydroxyacetaldehyde and hydroxyacetone are rather limited. For the determination of the millimeter- and sub-millimeter-wave spectrum of hydroxyacetaldehyde, Butler et al. (2001) estimated that the vapour pressure at room temperature was roughly $4 \mathrm{~Pa}{ }^{11}$ which is in good agreement with our determination of $(3 \pm 1) \mathrm{Pa}$ at $293 \mathrm{~K}$. On the contrary, Angove et al. (2006) reported an estimated value of about $5300 \mathrm{~Pa}$ at $298 \mathrm{~K}$, a value three orders of magnitude higher than our determination, $(4.9 \pm 0.3) \mathrm{Pa}$ at $298 \mathrm{~K}$. Besides, in measurements of UV absorption cross-section, Magneron et al. (2005) used partial pressures as high as $66 \mathrm{~Pa}$ at $298 \mathrm{~K}$, and $2100 \mathrm{~Pa}$ at $333 \mathrm{~K}^{23}$. If this value obtained at $333 \mathrm{~K}$ is roughly consistent with 
the vapor pressure of $980 \mathrm{~Pa}$ found in this work, their value reported at $298 \mathrm{~K}$ is approximately 20 times higher that our absolute determination. These discrepancies might be due to the presence of volatile impurities in hydroxyacetaldehyde in their study while they were removed, in the current work, after obtaining of hydroxyacelaldehyde monomers, by freeze-pump-thaw cycles.

Similarly, in experiments dedicated to Raman spectroscopy, the vapour pressure of hydroxyacetone was estimated to be less than $500 \mathrm{~Pa}$ at room temperature ${ }^{12}$. This reported upper limit is consistent with our determination of $(415 \pm 20) \mathrm{Pa}$ at $293 \mathrm{~K}$.

\section{Conclusion}

Our static device was tested to measure the vapour pressure of ethylene glycol and the obtained data shown an excellent agreement with those reported in the literature.

We have then measured the vapour pressures of hydroxyacetone and hydroxyacetaldehyde as a function of temperature. These data are the first direct measurements for these two compounds. They will be particularly valuable in laboratory studies where they are often necessary.

\section{Acknowledgement}

This work was supported by the French Ministry of Research through the LEFE/CHAT program. This work was also sponsored in part by the region of Alsace and the REseau Alsace de Laboratoires en Ingénierie et Sciences pour l'Environnement (REALISE). 


\section{Literature cited}

(1) Butkovskaya, N. I.; Pouvesle, N.; Kukui, A.; Mu, Y.; Le Bras, G. Mechanism of the OH-Initiated Oxidation of Hydroxyacetone over the Temperature Range 236-298 K, J. Phys. Chem. A 2006, 110, 6833.

(2) Carter, W. P. L.; Atkinson, R. Development and Evaluation of a Detailed Mechanism for the Atmospheric Reactions of Isoprene and NOx, Int. J. Chem. Kinet. 1996, 28, 497.

(3) Orlando, J. J.; Tyndall, G. S.; Paulson, S. E. Mechanism of the OH-Initiated Oxidation of Methacrolein, Geophys. Res. Lett. 1999, 26, 2191.

(4) Butkovskaya, N. I.; Pouvesle, N.; Kukui, A.; Le Bras, G. Mechanism of the OHInitiated Oxidation of Glycolaldehyde over the Temperature Range 233-296 K, J. Phys. Chem. A 2006, 110, 13492.

(5) Niki, H.; Maker, P. D.; Savage, C. M.; Hurley, M. D. Fourier transform infrared study of the kinetics and mechanisms for the chlorine-atom- and hydroxyl-radical-initiated oxidation of glycolaldehyde, J. Phys. Chem. 1987, 91, 2174.

(6) Orlando, J. J.; Tyndall, G. S.; Bilde, M.; Ferronato, C.; Wallington, T. J.; Vereecken, L.; Peeters, J. Laboratory and Theoretical Study of the Oxy Radicals in the $\mathrm{OH}-$ and ClInitiated Oxidation of Ethene, J. Phys. Chem. A 1998, 102, 8116.

(7) Ferronato, C.; Orlando, J. J.; Tyndall, G. S. Rate and mechanism of the reactions of $\mathrm{OH}$ and $\mathrm{Cl}$ with 2-methyl-3-buten-2-ol, J. Geophys. Res. 1998, 103, 25579.

(8) von Kuhlmann, R.; Lawrence, M. G.; Pöschl, U.; Crutzen, P. J. Sensitivities in global scale modeling of isoprene, Atmos. Chem. Phys. 2004, 4, 1.

(9) Matsunaga, S.; Wiedinmyer, C.; Guenther, A.; Orlando, J.; Karl, T.; Toohey, D. W.; Greenberg, J. P.; Kajii, Y. Isoprene oxidation products are a significant atmospheric aerosol component, Atmospheric Chemistry and Physics Discussions 2005, 5, 11143.

(10) Angove, D. E.; Fookes, C. J. R.; Hynes, R. G.; Walters, C. K.; Azzi, M. The characterization of secondary organic aerosol formed during the photodecomposition of 1,3butadiene in air containing nitric oxide, Atmos. Environ. 2006, 40, 4597.

(11) Butler, R. A. H.; De Lucia, F. C.; Petkie, D. T.; Mollendal, H.; Horn, A.; Herbst, E. The millimeter- and submillimeter-wave spectrum of glycolaldehyde (CH2OHCHO), Astrophys. Journal 2001, 134, 319.

(12) Mohacek-Grošev, V. Vibrational analysis of hydroxyacetone, Spectrochimica Acta Part A 2005, 61, 477-484.

(13) Junge, C. E. Basic considerations about traces constituents in the atmosphere as related to the fate of global pollutants, Fate of pollutants in Air and Water Environments, I.H. Suffet, Wiley, New York, part I. 1977.

(14) Rice, C. P.; Chernyak, S. M.; Mc Connell, L. L. Henry's Law Constants for pesticides measured as a function of temperature and salinity, J. Agric. Food Chemistry 1997, 45, 2291.

(15) Suntio, L. R.; Shiu, W. Y.; Mackay, D.; Seiber, J. N.; Glotfeldy, D. Critical review of Henry's law constants for pesticides, Rev. Envir. Contam. Toxicol. 1988, 103, 1.

(16) Staudinger, J.; Roberts, P. J. A critical review of Henry's law constants fir environmental applications., Crit. Rev. Environ. Sci. Technol. 1996, 26, 205.

(17) Iannone, M. Vapor Pressure Measurements in a Closed System, Journal of Chemical 
Education 2006, 83.

(18) Tuazon, E. C.; Atkinson, R. A product study of the gas-phase reaction of methyl vinyl ketone with the $\mathrm{OH}$ radical in the presence of NOx, Int. J. Chem. Kinet. 1989, 21, 1141-1152.

(19) Stull, D. R. Vapor Pressure of Pure Substances. Organic and Inorganic Compounds, Industrial and Engineering Chemistry 1947, 39, 517.

(20) Knauth, P.; Sabbah, R. Energetics of intra- and intermolecular bonds in w-alkanediols (II) Thermochemical study of 1,2-ethanediol, 1,3-propanediol, 1,4-butanediol, and 1,5pentanediol at 298.15K, Struct. Chem. 1990, 1, 43.

(21) Gardner, P. J.; Hussain, K. S. The standard enthalpies of formation of some aliphatic diols, J. Chem. Thermodyn. 1972, 4, 819.

(22) Pedley, J. B.; Naylor, R. D.; Kirby, S. P. Thermochemical Data of Organic Compounds, Chapman and Hall, New York 1986, 1.

(23) Magneron, I.; Mellouki, A.; Le Bras, G.; Moortgat, G. K.; Horowitz, A.; Wirtz, K. Photolysis and $\mathrm{OH}-$ Initiated Oxidation of Glycolaldehyde under Atmospheric Conditions, $J$. Phys. Chem. A 2005, 109, 4552. 
Table 1: Experimental vapour pressures of ethylene glycol measured in this work and comparison with the literature. $100 \times \Delta \mathrm{P}^{\circ} / \mathrm{P}^{\circ}$ corresponds to the percentage deviation between experimental and literature values.

\begin{tabular}{|c|c|c|c|}
\hline $\mathbf{T} / \mathrm{K}$ & $\mathbf{P}_{\text {lit }}^{\circ}{ }^{(\mathbf{a})} / \mathbf{P a}$ & $\mathbf{P}^{\circ}(\mathbf{b}) / \mathbf{P a}$ & $100 \times \Delta \mathbf{P}^{\circ} / \mathbf{P}^{\circ}(\mathrm{c})$ \\
\hline $307.7( \pm 0.1)$ & $26( \pm 1)$ & $28( \pm 1)$ & 0.81 \\
\hline $312.6( \pm 0.1)$ & $39( \pm 2)$ & $41( \pm 2)$ & 1.30 \\
\hline $316.5( \pm 0.1)$ & $52( \pm 3)$ & $55( \pm 3)$ & 2.52 \\
\hline $318.8( \pm 0.1)$ & $62( \pm 3)$ & $61( \pm 3)$ & 5.12 \\
\hline $322.1( \pm 0.1)$ & $79( \pm 4)$ & $77( \pm 4)$ & 5.38 \\
\hline $326.1( \pm 0.1)$ & $124( \pm 6)$ & $124( \pm 6)$ & 0 \\
\hline $328.2( \pm 0.1)$ & $128( \pm 6)$ & $137 \pm(23)$ & 0.74 \\
\hline $334.5( \pm 0.2)$ & $192( \pm 10)$ & $196( \pm 13)$ & 2.11 \\
\hline $335.2( \pm 0.2)$ & $201( \pm 10)$ & $201( \pm 14)$ & 0.11 \\
\hline $340.2( \pm 0.2)$ & $282( \pm 14)$ & $278( \pm 19)$ & 0.37 \\
\hline $347.9( \pm 0.2)$ & $464( \pm 23)$ & $454( \pm 32)$ & 0.03 \\
\hline $359.2( \pm 0.2)$ & $923( \pm 46)$ & $900( \pm 58)$ & 1.32 \\
\hline $367.9( \pm 0.2)$ & $1528( \pm 76)$ & $1483( \pm 91)$ & 1.98 \\
\hline $373.4( \pm 0.2)$ & $2086( \pm 104)$ & $1950( \pm 131)$ & 1.02 \\
\hline $384.5( \pm 0.2)$ & $3772( \pm 189)$ & $3467( \pm 236)$ & 1.29 \\
\hline
\end{tabular}

(a) The quoted uncertainties correspond to $2 \sigma$ level $+5 \%$ where $\sigma$ is the standard deviation of the linear fit of the plot of $\log _{10} P_{\text {lit }}$ vs $1 / T^{19}$.

(b) The quoted uncertainties correspond to $2 \sigma$ level $+5 \%$.

(c) The deviation between the experimental and literature values is defined as follows:

$$
\frac{\Delta P^{\circ}}{P^{\circ}}=\left(\frac{P^{\circ}-P^{\circ}{ }_{l i t}}{P^{\circ}}\right)
$$


Table 2: Experimental vapour pressures of both hydroxyacetaldehyde and hydroxyacetone measured in this work. The quoted uncertainties correspond to $2 \mathrm{~s}$ Level $+5 \%$.

\begin{tabular}{|c|c|c|c|c|c|}
\hline \multicolumn{3}{|c|}{ Hydroxyacetaldehyde } & \multicolumn{3}{|c|}{ Hydroxyacetone } \\
\hline $\mathbf{T} / \mathbf{K}$ & $\mathbf{P}^{\circ} / \mathbf{P a}$ & $100 \times \Delta \mathrm{P}^{\circ} / \mathrm{P}^{\circ}(\mathrm{a})$ & $\mathbf{T} / \mathbf{K}$ & $\mathbf{P}^{\circ} / \mathrm{Pa}$ & $100 \times \Delta \mathbf{P}^{\circ} / \mathrm{P}^{\circ}(\mathrm{a})$ \\
\hline 295.85 & $3.7( \pm 0.2)$ & 0.44 & 273.22 & $127( \pm 9)$ & 3.26 \\
\hline 305.10 & $9.0( \pm 0,5)$ & 5.24 & 275.48 & $136( \pm 9)$ & 4.73 \\
\hline 305.51 & $9.6( \pm 1.2)$ & 2.26 & 277.78 & $162( \pm 11)$ & 2.59 \\
\hline 319.50 & $33( \pm 3)$ & 2.72 & 278.55 & $167( \pm 11)$ & 4.44 \\
\hline 319.84 & $33( \pm 3)$ & 0.00 & 278.55 & $172( \pm 11)$ & 1.55 \\
\hline 322.38 & $37( \pm 3)$ & 6.37 & 280.90 & $201( \pm 42)$ & 0.48 \\
\hline 323.64 & $46( \pm 3)$ & 2.06 & 281.69 & $205( \pm 13)$ & 3.52 \\
\hline 327.73 & $62( \pm 5)$ & 1.38 & 281.69 & $210( \pm 13)$ & 1.47 \\
\hline 333.04 & $98( \pm 10)$ & 4.01 & 289.86 & $356( \pm 21)$ & 1.74 \\
\hline 339.32 & $154( \pm 9)$ & 2.14 & 290.70 & $360( \pm 21)$ & 2.25 \\
\hline 340.91 & $170( \pm 10)$ & 0.74 & 290.70 & $363( \pm 21)$ & 1.23 \\
\hline 341.95 & $182( \pm 12)$ & 0.15 & 290.70 & $360( \pm 21)$ & 2.25 \\
\hline 342.82 & $198( \pm 15)$ & 2.57 & 293.26 & $431( \pm 25)$ & 0.84 \\
\hline 346.83 & $253( \pm 18)$ & 1.33 & 295.86 & $516( \pm 30)$ & 3.83 \\
\hline \multirow[t]{7}{*}{355.98} & $486( \pm 26)$ & 2.00 & 295.86 & $495( \pm 29)$ & 0.10 \\
\hline & & & 296.74 & $531( \pm 31)$ & 1.90 \\
\hline & & & 300.30 & $617( \pm 35)$ & 3.04 \\
\hline & & & 301.20 & $642( \pm 36)$ & 4.05 \\
\hline & & & 302.11 & $717( \pm 40)$ & 2.03 \\
\hline & & & 303.03 & $746( \pm 42)$ & 1.06 \\
\hline & & & 303.95 & $817( \pm 46)$ & 4.96 \\
\hline
\end{tabular}

(a) The individual deviation $\Delta \mathrm{P}^{\mathrm{o}} / \mathrm{P}^{\mathrm{o}}$ is calculated as follows: $\Delta \mathrm{P}^{\mathrm{o}} / \mathrm{P}^{\mathrm{o}}=\left(\mathrm{P}^{\circ}-\mathrm{P}^{\circ}\right.$ Antoine $\left.\left.) / \mathrm{P}^{\circ}\right)\right)$ where $\mathrm{P}^{\circ}$ Antoine is calculated from the simplified Antoine's equation and $\mathrm{P}^{\circ}$ is the experimental value. 


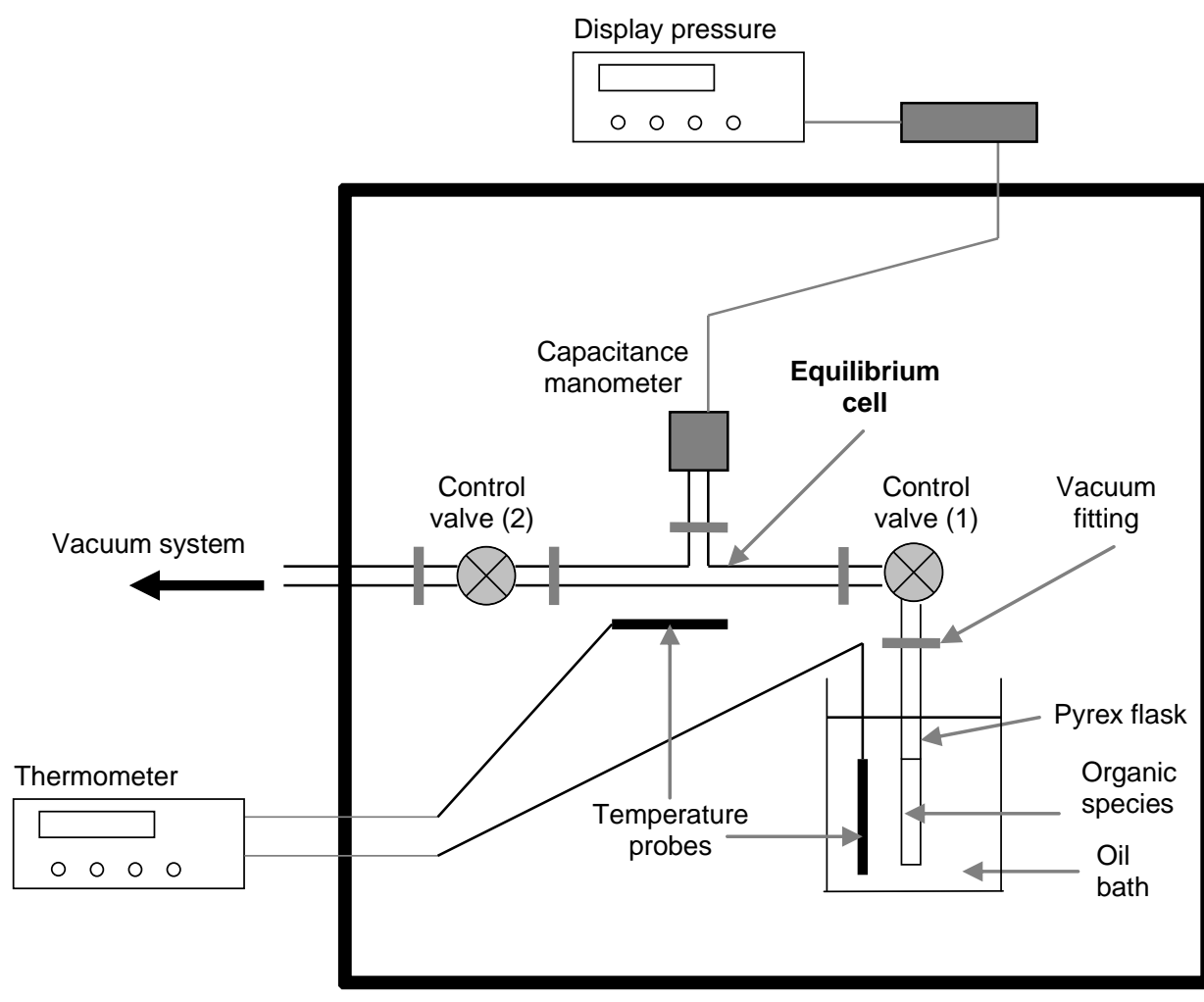

OVEN

Figure 1: Schematic diagram of vapour pressure apparatus. 


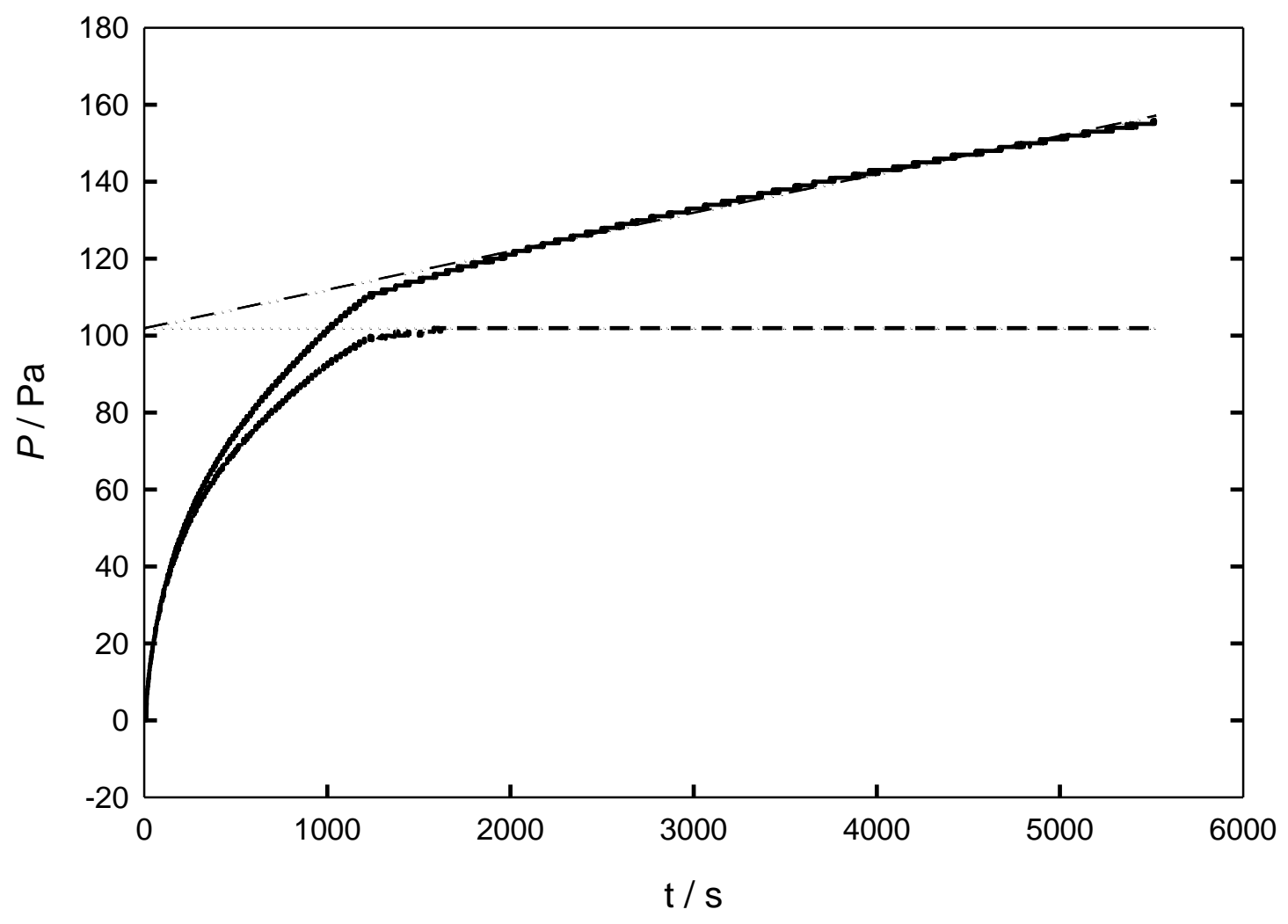

Figure 2: Plot of both $\mathrm{P}$ (solid line) and $\mathrm{P}_{\text {corrected }}$ (short dash line) recorded as a function of time during an experiment performed on ethylene glycol at $326.1 \mathrm{~K}$. The leak rate is determined from the slope of the linear asymptote (dash-dot-dot line). 


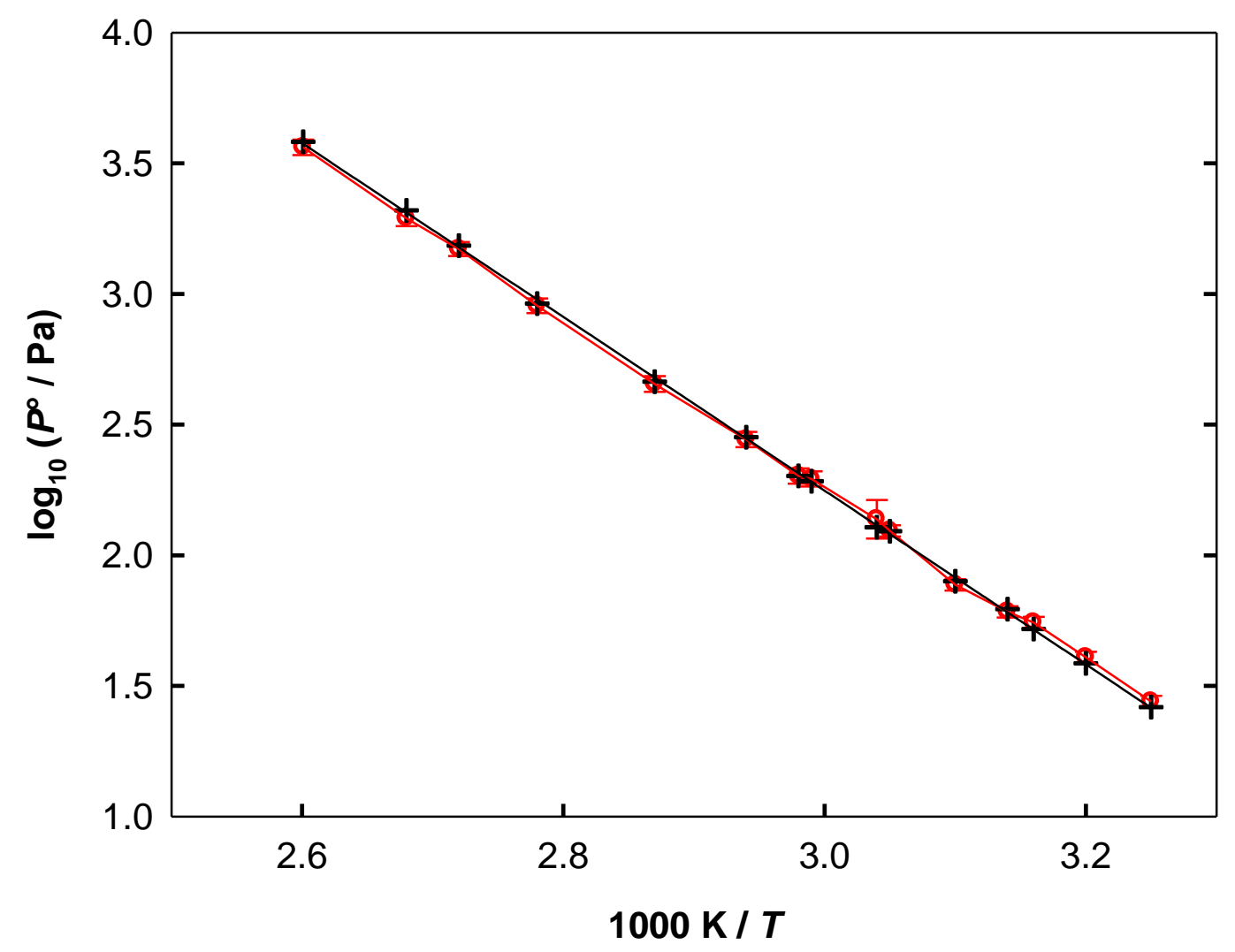

Figure 3: Comparison for vapour pressures of ethylene glycol measured from this study (red circles) and those from literature ${ }^{19}$ (black cross) and the resulting fits using the simplified Antoine's equation (see solid lines). The quoted uncertainties on experimental data correspond to $2 \sigma$ Level $+5 \%$ (see text). 


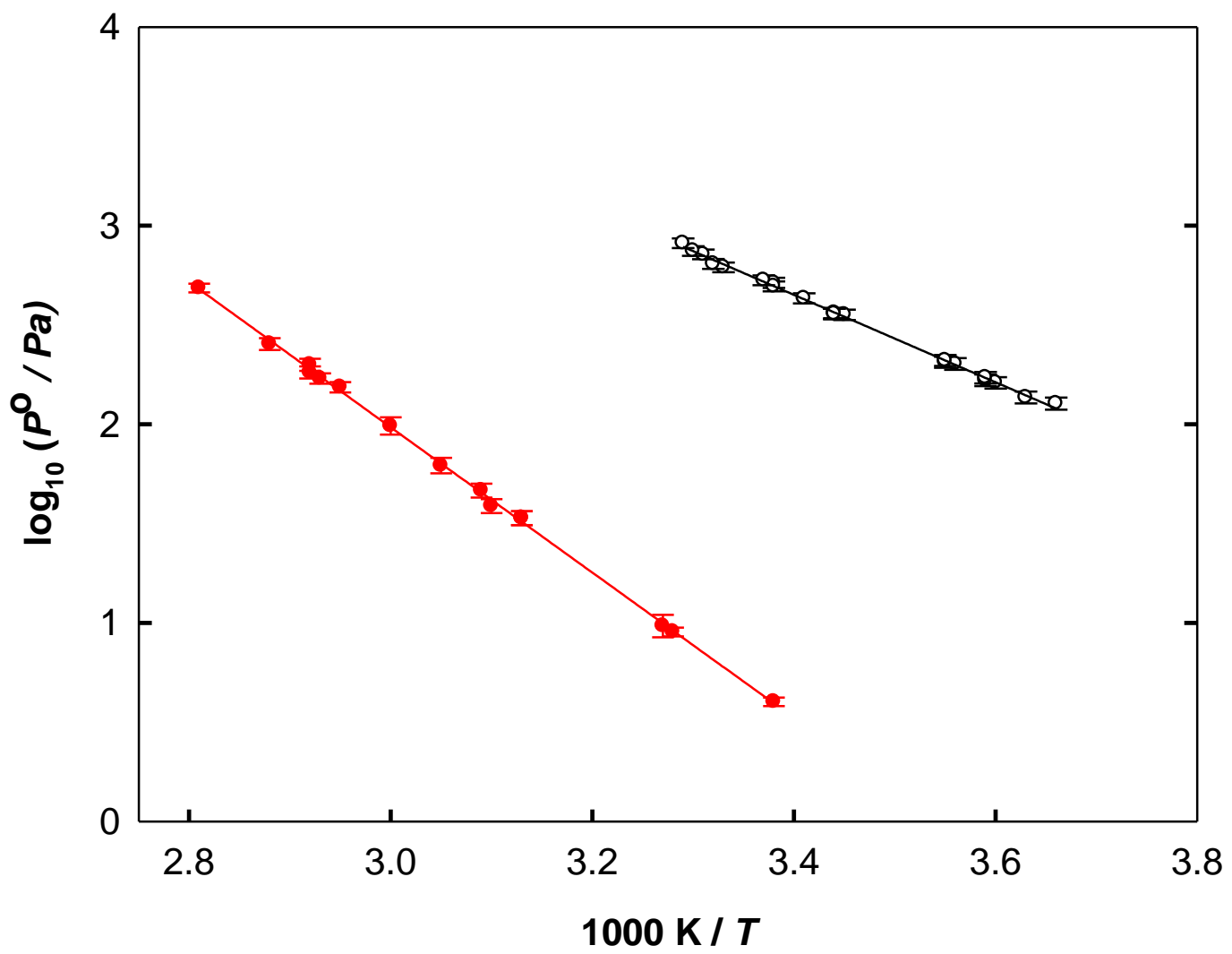

Figure 4: Plot of the $\log _{10}\left(P^{\circ} / \mathrm{Pa}\right)$ as a function of $1000 / T$ for $(\bullet)$ hydroxyacetaldehyde and $(\bigcirc)$ hydroxyacetone. The solid lines correspond to the fit using the simplified Antoine's equation. The quoted uncertainties on experimental data correspond to $2 \sigma$ Level $+5 \%$ (see text). 